\title{
Structure/function relationships of lipoteichoic acids
}

\author{
Siegfried Morath ${ }^{1,2}$, Sonja von Aulock ${ }^{1}$, Thomas Hartung ${ }^{1,2}$ \\ ${ }^{2}$ Department of Biochemical Pharmacology, University of Konstanz, Konstanz, Germany \\ ${ }^{2}$ European Center for the Validation of Alternative Methods (ECVAM), Joint Research Center, Ispra, Italy
}

\begin{abstract}
The role of lipoteichoic acids (LTAs) from Gram-positive bacteria as immunostimulatory molecules was controversial for many years, as inadequate preparation methods as well as heterogeneous and endotoxin-contaminated commercial preparations led to conflicting results. An improved purification methodology for LTA now yields potent bioactive and chemically defined material, which is currently being characterized in various models. A synthetic analogue of Staphylococcus aureus LTA has proven the structure/function relationship. The key role of D-alanine esters for the immune response of LTA was confirmed by synthetic derivatives. The glycolipid anchor of LTA plays a central role analogous to the lipid A of LPS. Methodological aspects and criteria for quality assessment of LTA preparations are discussed.
\end{abstract}

Keywords: Lipoteichoic acid, purification, structural identification, structure/function relationship

\section{INTRODUCTION}

Successful therapeutic treatment of sepsis, i.e. a systemic reaction of the body to a bacterial infection, is one of the greatest open clinical challenges, as the lethality of sepsis remains between $40-60 \%$. Lipopolysaccharides (LPSs), components of the Gram-negative bacterial envelope, are generally accepted as initiators of septic shock and the inflammatory mechanisms initiated by LPS have been well characterized. ${ }^{1}$ Far less is known about the interactions of bacterial and host structures in Gram-positive septic shock, although the incidence of Gram-positive sepsis ${ }^{2,3}$ and the incidence of resistance of these bacteria towards antibiotics ${ }^{4}$ has increased greatly in the last decades. Surprisingly, the clinical symptoms of sepsis caused by Gram-positive or Gram-negative bacteria are practically identical, although Gram-positive bacteria have no LPS.

The structural and functional Gram-positive analogue of Gram-negative LPS appears to lie in the class of lipotei-

Correspondence to: Thomas Hartung MD PhD, University of Konstanz, Biochemical Pharmacology, POB M655, 78457 Konstanz, Germany. Tel: +49 7531 884116; Fax: +49 7531884117 ;

E-mail: Thomas.Hartung@uni-konstanz.de choic acids (LTAs). Like LPS, LTA is an amphiphile. LTA is commonly composed of a hydrophilic backbone with repetitive glycerophosphate units and D-alanine or hexose substituents as well as a lipophilic glycolipid.

Some activities of LTA were recognized before the chemical nature of this substance class was elucidated. In 1953, Harris and Harris ${ }^{5}$ described a factor that could bind erythrocytes in the culture supernatant of group A streptococci. The binding of this 'sensibilization factor' (SF) was shown by the coagulation of the erythrocytes upon addition of antibodies raised against the whole bacteria. SF was extracted from streptococci and staphylococci with phenol and it was postulated that SF was attached to Gram-positive bacteria and could be released by them. ${ }^{6}$ Ten years later, Jackson and Moskowitz ${ }^{7}$ showed that the phenol-extracted SF was composed of an alanine-substituted polyglycerophosphate (PGP). Independently, Dishon et al. ${ }^{8}$ discovered that carbohydrates were components of SF and also observed spontaneous binding of SF to various other animal cell types. The term lipoteichoic acid (Greek: teichos, wall) was first used by Wicken and $\mathrm{Knox}^{9}$ and was coined by Hewett et al. ${ }^{10}$ in 1970 to describe a polymer made up of a polyglycerophosphate-ester coupled to a glycolipid (specifically kojibiose coupled to palmitic acid).

LTA was originally defined as a polymer of repetitive 1,3-phosphodiester-linked glycerol-1-phosphate units 


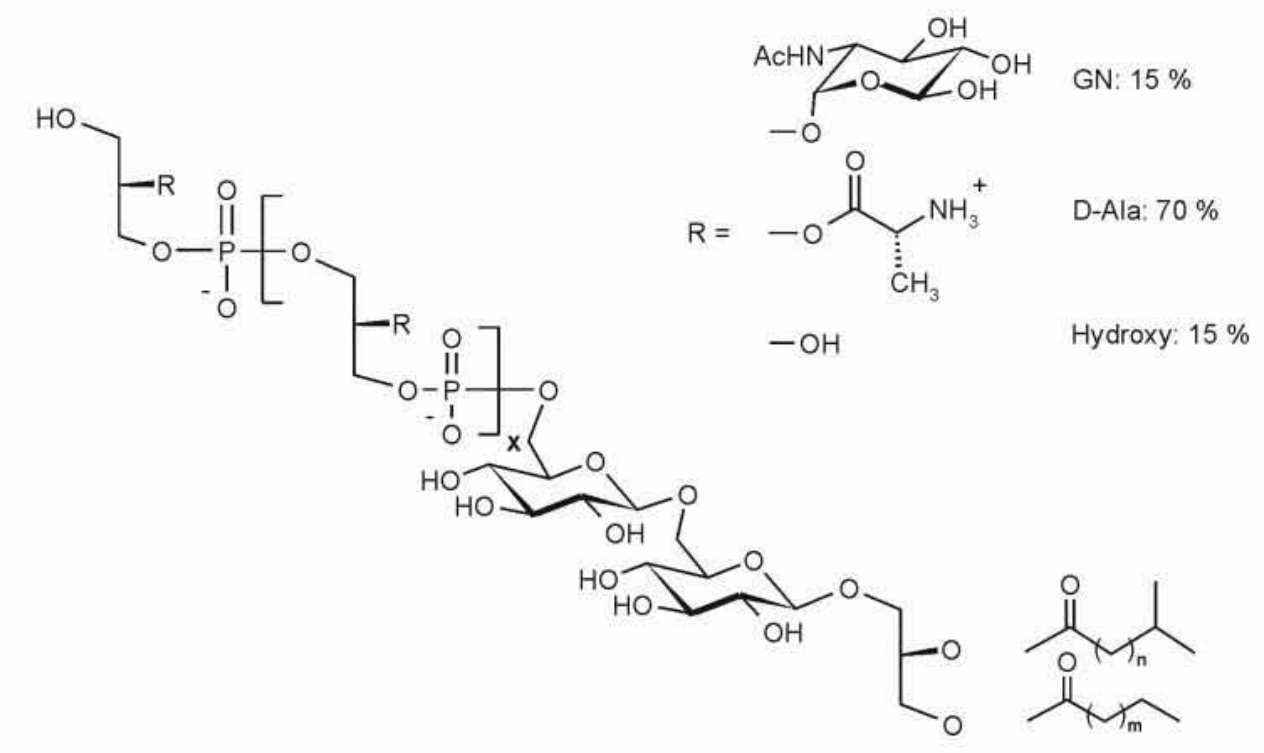

Fig. 1. Chemical structure of LTA from S aureus DSM 20233. The degree of polymerization $(\mathrm{x})$ ranges between 45 and 50 . The fatty acids consist of ( $\mathrm{m}, \mathrm{n}$ $=\mathrm{C}_{14}-\mathrm{C}_{19}$ ) alkyl chains, which are particularly methylated at positions 9,14 and 17 . The average ratios of substituents are given.

with a glycolipid anchor. The polyglycerophosphate (PGP) part is substituted with D-alanine and sugar residues. Variations in the deg ree of substitution and PGP chain length convey a microheterogeneous character to LTA. ${ }^{11}$ However, it has become increasingly obvious that the term LTA can no longer be used to describe a uniform structu ral principle and a flexible defin ition was suggested in $1994 .{ }^{12}$ Th is defines LTA as being a macro-amphiphile, containing alditolphosphate in the hydrophilic chain. This revised definition includes both polyglycerophosphate and polyribitolphosphate back bones.

\section{STRUCTURE/FUNCTION RELATIONSHIP OF LTA}

The analogy of the structure/function relationship between LPS and LTA motivated many studies in the 1980 s and $1990 \mathrm{~s}$, which aimed at investigating the role of LTA in Gram-positive septic shock. Many of these investigations concluded that LTA represents an important immunostimulatory principle. However, the often conflicting publications left the role of LTA controversial. Especially, LTA of Staphylococcus cureus, the most prevalent Gram-positive pathogen, obtained from a commercial source and purified by a standardized procedure, proved to be biologically inactive. ${ }^{13-15}$

\section{Structure/function relationship in cytokine induction of LTA from $S$. aureus}

Over many decades, LTA was routinely prepared by adopting the phenol extraction method commonly employed for
Gram-negative bacterial LPS isolation. To test whether this procedure might inactivate LTA from $S$. cureus, the original extraction protocols were modified and the chemical structure (Fig. 1) and immunostimulatory activity of the resulting LTA preparations (Fig. 2) were characterized. ${ }^{16}$

The main modifications to the procedure were the introduction of butanol extraction instead of phenol, which also enabled extraction at room temperature. Butanol had been used previously to extract bacterial amphiphiles followed by other chromatography steps. ${ }^{17.18}$ Also, the use of the volatile ammonium acetate buffer for hydrophobic interaction chromatography (HC) eliminated a later dialysis step. ${ }^{19}$ The resulting LTA ( $>99 \%$ purity) displayed immunostimulatory potency regarding pro-inflammatory cytokine induction similar to that of LPS from Psendomonas aeruginosa. Contamination with LPS could be excluded $(<6$ parts LPS per billion parts LTA) by Limulus amoebocyte lysate assay (LAL). The recent rapid methodological developments in nuclear magnetic resonance (NMR) spectroscopy enabled the first quantitative, non-destructive analysis of an intact LTA and proved the ratio between glycerophosphate chain, D-alanine and $N$-acetylglucosamine substituents, and glycolipid anchor (Fig. 1). Fatty acid composition was determined by gas chromatography/mass spectrometry after methanolysis. Hydrofluoric acid hydrolysis was performed to separate the glycolipid anchor. This was subjected to silica gel chromatography. The composition of the fatty acids of the glycolipid and the intact LTA were compared additionally by GC-MS electron impact induced fragment generation. ${ }^{16}$

The comparison between the active LTA gained by the amended purification procedure and phenol-extracted 


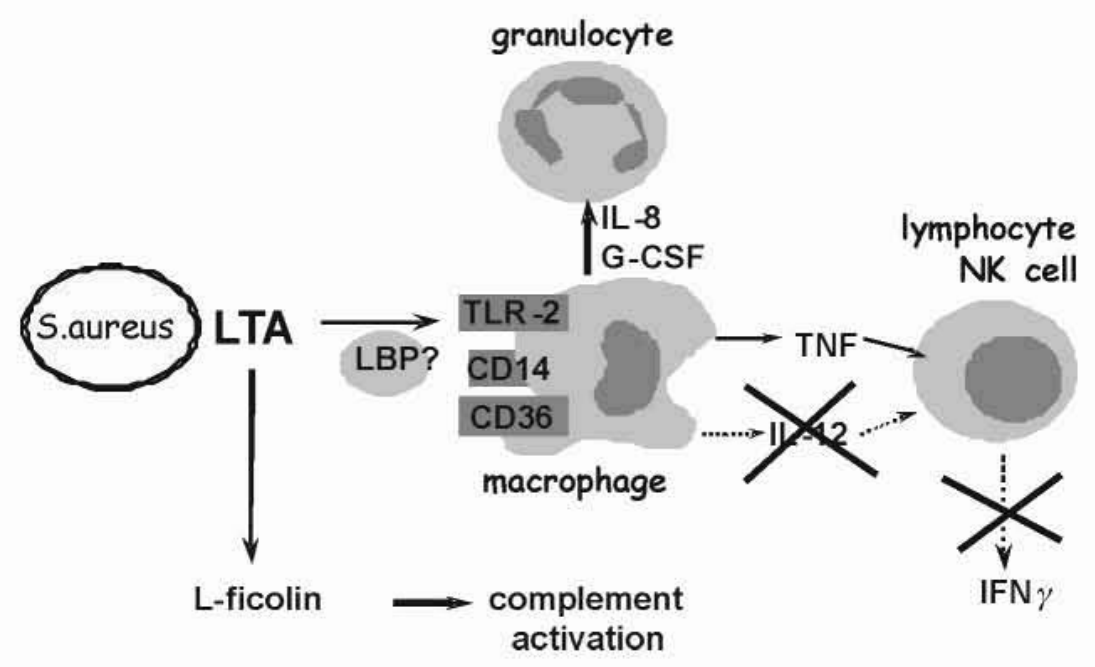

Fig. 2. Overview of the innate immune response to LTA. LTA from S aureus activates macrophages via TLR-2, CD14 and CD36; the role of LBP is still unclear. This activation induces a strong recruitment signal for granulocytes via IL 8 and G-CSF release. Due to a lack of IL-12 production by macrophages, lymphocytes and NK cells are not induoed to release IFN- $\gamma$. LTA activates the complement system by direct binding to L-ficolin.

material with lower immunostimulatory activity, showed a significantly lower Dalanine content in the latter LTA. Furthermore, the specific hydrolysis of alanine esters of the LTA led to a correlating decimation of the immunostimulatory activity. Further, new insights into the structure of LTA were the significantly greater chain length of the polyglycerophosphate and the presence of $N$-acetylglucosamine substituents on this 'backbone'. Thus, the controversy about the role and significance of LTA as a Gram-positive immune stimulus appeared to have been based mainly on insufficient and incomplete structure/ function analyses of LTA.

\section{Structural degradation and heterogeneity of comm ercial LTA preparations}

Based on these results, the discrepancies between the differing activities of commercial preparations of LTA and inhouse extractions by the modified protocol were investigated. ${ }^{20}$ Conflicting results regarding the immunoactivating properties of commercial and in-house isolated LTA had already been described in 1992 by Keller $e t$ al. ${ }^{13}$ Fractionation of commercial preparations of LTA using HIC followed by NMR analysis showed an inhomogeneous composition of this material. The LTA contained in the preparations was partially degraded. Thus, the LTA content was only, on average, $61 \%$ in preparations from Streptococcus pyogenes, $16 \%$ in Bacillus subtilis material and $75 \%$ in $S$ caureus preparations. The degradation process resulted in LTAs with shorter PGP chain len gths as well as loss of D-alanine and $N$-acetylglucosamine substituents. Based on their elution profiles after HIC, the lack of phosphate and negative LAL test results, all these preparations contained further non-LTA- and non-LPS-like immunostimulatory components in differing quantities. ${ }^{20}$ In contrast to the repurified commercial LTA from $S$. cureus, LTA from B. subtilis and Strep. pyogenes did induce the release of tumor necrosis factor (TNF)- $\alpha$, interleukin (IL)-1B, IL-6 and $\mathbb{L}-10$ in vitro in human whole blood. ${ }^{21}$ While the purified LTA prepared from this material contained irrelevant LPS contamination as shown in the LAL assay, the commercial preparations contained endotoxin equivalents of $10-100 \mathrm{ng} / \mathrm{mg}$ LTA. Furthermore, the LTA preparations from $B$. subtilis displayed significant nucleic acid content. In comparison to the butanol-extracted LTA, the repurified commercial LTA had up to 1000 -fold lower immunostimulatory potency. ${ }^{20}$ Thus, the unspecific content of the commercially available LTA preparations and the suboptimal phenol extraction have hindered the investigation of structure/function relationships in the past.

\section{Synthetic LTA of S. aureus is a potent stimulus for cytokine release}

As a definitive proof of the biological activity of LTA, a novel, chemically synthesized LTA designed on the basis of the new structural data showed functional activity analogous to LTA extracted from $S$. cureus. ${ }^{22,23}$ This synthetic LTA with six glycerophosphate units contained the same distribution of substituents as the LTA of bacterial origin: four D-alanine esters, one $N$-acetylglucosamine and glycerophosphate at position 2 was not substituted (Table 1; Fig. 3). Further, we found, by preparative isolation of the intact lipid anchor from native LTA, that this glycolipid is itself immunologically active regarding cytokine induction in human whole blood. In comparison with native LTA or synthetic LTA, about 600 times 
A

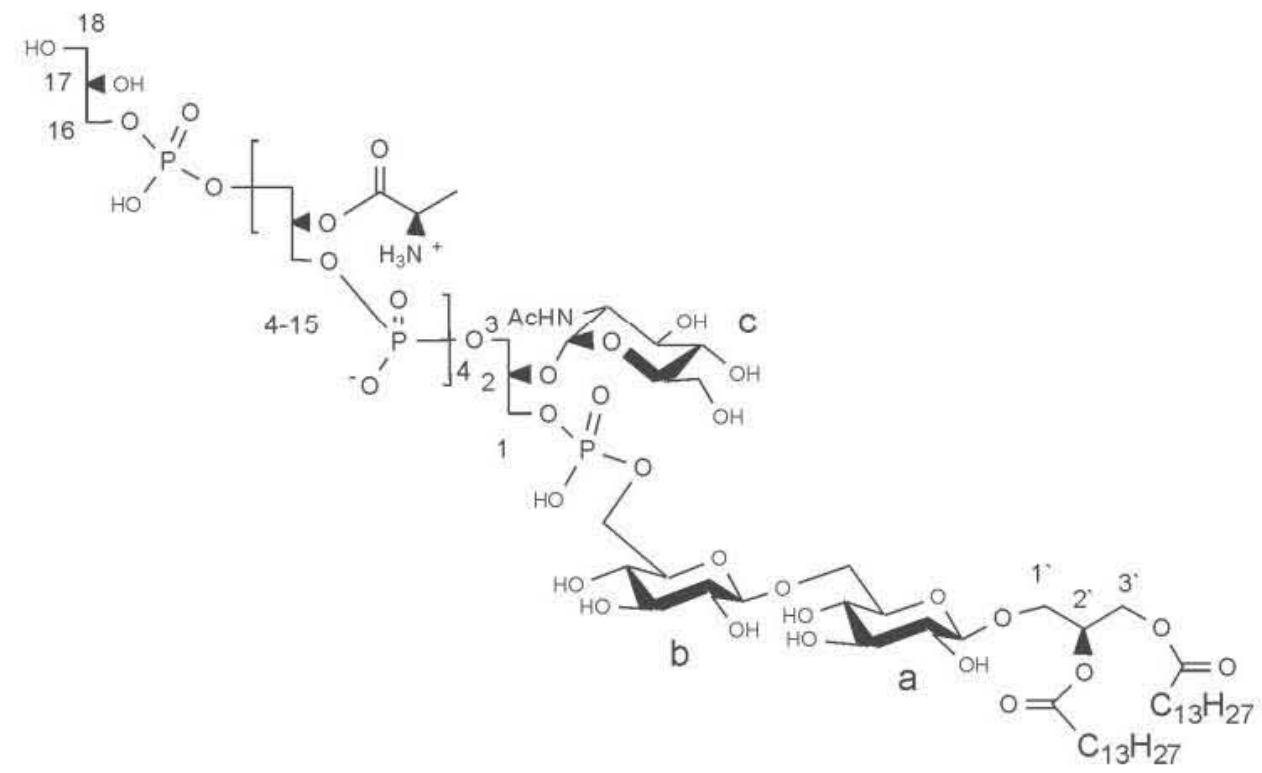

B

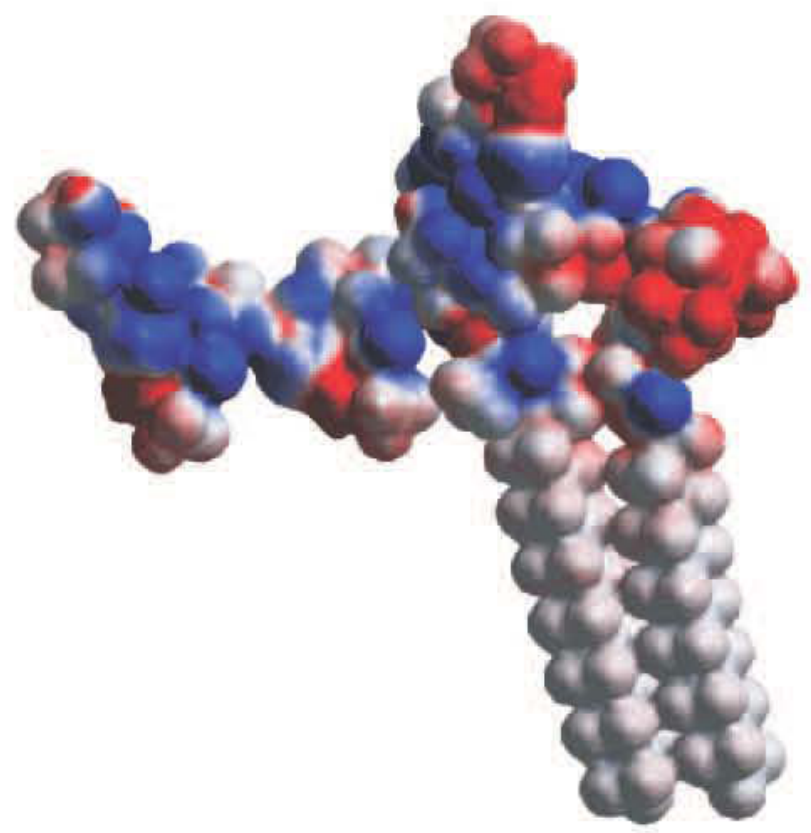

Fig. 3. (A) Chemical structure of synthetic LTA; a and b, gentiobiose rings, c, $N$-acetyl glucosamine (see also Table 1). (B) Display of charged and uncharged regions of synthetic LTA by semi-empirical calculation of HOMO/LUMO orbitals (Extended Hueckel method; negative partial charges in blue, positive partial charges in red).

more molecules of the lipid anchor were required to induce cytokine release. This finding was verified by the analogous synthetic structure. However, at the same molarity, a natural glycolipid with only one fatty acid hardly induced any cytokine release. Experiments with murine peritoneal cells showed that native LTA as well as the synthetic glycolipid have the same receptor dependency (TLR-2), in contrast to LPS which requires TLR- $4 .^{23.24}$ The role of the D-alanine substituents could finally be proven with synthetic LTA derivatives with L-alanine substituents, which were less active by a factor of 100 , showing stereoselective recognition of the stimulus at the polyglycerophosphate backbone..$^{23,25}$ Structural derivatives of the synthetic LTA showed that the $N$-acetylglucosamine substituent and the gentiobiose sugar play no role in the induction of cytokine release. ${ }^{25}$

The availability of highly pure, well-characterized and bioactive LTA preparations has stimulated a great number of studies on this molecule to define its biological properties anew (overview in Fig. 2). It was demonstrated that LTA employs CD14, LBP and also CD36 for cytokine induction ${ }^{26-28}$ and induces a strong release of 
Table 1. ${ }^{1} \mathrm{H},{ }^{13} \mathrm{C}$-Heteronuclear multiple-quantum coherence (HMQC) assignments of synthetic lipoteichoic acid

\begin{tabular}{|c|c|c|c|}
\hline 150.4 & & & $\begin{array}{c}600 \\
\end{array}$ \\
\hline & GleNAc ring $\mathrm{c}$ & & \\
\hline 22.6 & $\mathrm{Ac}$ & $\mathrm{Ac}$ & 2.1 \\
\hline 97.2 & $1 \mathrm{c}-\mathrm{C}$ & $1 \mathrm{c}-\mathrm{H}$ & 5.1 \\
\hline 54.0 & $2 c-C$ & $2 \mathrm{c}-\mathrm{H}$ & 3.96 \\
\hline 71.4 & $3 c-C$ & $3 \mathrm{c}-\mathrm{H}$ & 3.82 \\
\hline 70.3 & $4 c-C$ & $4 \mathrm{c}-\mathrm{H}$ & 3.52 \\
\hline 72.4 & $5 c-C$ & $5 \mathrm{c}-\mathrm{H}$ & 3.95 \\
\hline \multirow[t]{3}{*}{60.9} & $6 c-C$ & $6 \mathrm{c}-\mathrm{H}$ & $3.82+3.91$ \\
\hline & Gentiobiose ring a & & \\
\hline & $1 \mathrm{a}-\mathrm{C}$ & $1 \mathrm{a}-\mathrm{H}$ & 4.47 \\
\hline 73.4 & $2 a-C$ & $2 \mathrm{a}-\mathrm{H}$ & 3.31 \\
\hline \multirow[t]{6}{*}{75.9} & $3 \mathrm{a}-\mathrm{C}$ & $3 \mathrm{a}-\mathrm{H}$ & 3.51 \\
\hline & $4 a-C$ & $4 \mathrm{a}-\mathrm{H}$ & 3.41 \\
\hline & $5 \mathrm{a}-\mathrm{C}$ & $5 \mathrm{a}-\mathrm{H}$ & 3.63 \\
\hline & $6 \mathrm{a}-\mathrm{C}$ & $6 \mathrm{a}-\mathrm{H}$ & \\
\hline & Gentiobiose ring $b$ & & \\
\hline & $1 \mathrm{~b}-\mathrm{C}$ & $1 \mathrm{~b}-\mathrm{H}$ & 4.52 \\
\hline 73.4 & $2 b-C$ & $2 \mathrm{~b}-\mathrm{H}$ & 3.35 \\
\hline \multirow[t]{5}{*}{75.9} & $3 b-C$ & $3 b-\mathrm{H}$ & 3.52 \\
\hline & $4 b-C$ & $4 \mathrm{~b}-\mathrm{H}$ & \\
\hline & $5 b-C$ & $5 b-\mathrm{H}$ & \\
\hline & $6 \mathrm{~b}-\mathrm{C}$ & $6 \mathrm{~b}-\mathrm{H}$ & \\
\hline & Glycerol - fatty acid & & \\
\hline \multirow[t]{2}{*}{68.2} & $1^{\prime}-\mathrm{C}$ & $1^{\prime}-\mathrm{H}$ & $3.87+4.07$ \\
\hline & $2^{\prime}-\mathrm{C}$ & $2^{\prime}-\mathrm{H}$ & 5.35 \\
\hline \multirow[t]{2}{*}{64} & $3^{\prime}-\mathrm{C}$ & $3^{\prime}-\mathrm{H}$ & $4.44+4.27$ \\
\hline & Glycerol - GlcNAc & & \\
\hline 65.5 & $1-\mathrm{C}$ & $1-\mathrm{H}$ & $4.53+4.47$ \\
\hline 76.2 & $2-\mathrm{C}$ & $2-\mathrm{H}$ & 4.05 \\
\hline \multirow[t]{2}{*}{65.5} & $3-\mathrm{C}$ & $3-\mathrm{H}$ & $4.53+4.47$ \\
\hline & Glycerol - Ala 4-15 & & \\
\hline 64 & $\mathrm{CH}_{2}-\mathrm{C}$ & $\mathrm{CH}_{2}-\mathrm{H}$ & 4.11 \\
\hline 74.4 & $\mathrm{CH}-\mathrm{Ala}-\mathrm{C}$ & CH-Ala-H & 5.39 \\
\hline \multirow[t]{2}{*}{64} & $\mathrm{CH}_{2}-\mathrm{C}$ & $\mathrm{CH}_{2}-\mathrm{H}$ & 4.11 \\
\hline & Glycerol & & \\
\hline 66.8 & $16-\mathrm{C}$ & $16-\mathrm{H}$ & $3.88+3.92$ \\
\hline 71.1 & $17-\mathrm{C}$ & $17-\mathrm{H}$ & 3.91 \\
\hline \multirow[t]{2}{*}{62.4} & $18-\mathrm{C}$ & $18-\mathrm{H}$ & $3.62+3.69$ \\
\hline & Alanine & & \\
\hline 15.9 & $\mathrm{CH}_{3}-\mathrm{C}$ & $\mathrm{H}_{3}-\mathrm{H}$ & 1.63 \\
\hline \multirow[t]{2}{*}{49.2} & $\mathrm{CH}-\mathrm{C}$ & $\mathrm{CH}-\mathrm{H}$ & 4.3 \\
\hline & Fatty acid & & \\
\hline 14.2 & $\mathrm{R}-\mathrm{CH}_{3}$ & R-CH & 0.88 \\
\hline 30.5 & $-\left(\mathrm{CH}_{2}\right)_{10^{-}}$ & $-\left(\mathrm{CH}_{2}\right)_{10^{-}}$ & 1.3 \\
\hline 25.4 & $\mathrm{CO}-\mathrm{CH}_{2}-\mathrm{CH}_{2}-$ & $\mathrm{CO}-\mathrm{CH}_{2}-$ & 1.61 \\
\hline 34.5 & $\mathrm{CH}_{2}-\mathrm{CO}-\mathrm{CH}_{2}-\mathrm{CH}_{2}-$ & $\mathrm{CO}-\mathrm{CH}_{2}-\mathrm{CH}_{2}-$ & $2.35 / 2.4$ \\
\hline
\end{tabular}

the chemo-attractants LTB ${ }^{4}$, IL-8, C5a, MCP-1 and G-CSF in whole blood at least comparable to stimulation with the same concentration of LPS (Salmonella abortus equi). ${ }^{29}$ LTA induces procoagulant activity in monocytes, ${ }^{30}$ but does not stimulate or prime neutrophils. ${ }^{29}$ LTA specifically binds to L-ficolin and these complexes initiate lectin pathway-dependent $\mathrm{C} 4$ turnover. ${ }^{31}$

\section{QUALITY ASSESSMENT OF LTA PREPARATIONS}

The scientific literature describes many biological effects of LTA in a broad spectrum of test systems, employing a large assortment of raw or uncharacterized extracts as immunological stimuli. The validity of results emerging under such conditions is clearly doubtful. The primary goal should be a clear-cut allocation of a biological effect to a molecular substance with proven purity.

Following the publication of the optimized preparation procedure for LTA, numerous groups world-wide have started to work with this material and some plan to prepare LTA themselves. The following section discusses the methodological possibilities and critical variables in the preparation of LTA as well as criteria which should be considered for the quality control of LTA preparations.

\section{Criteria for the purity of LTA}

What is meant by purity? LTA and LPS preparations were purified sufficiently for chemical and structural studies decades ago. A contamination level of $1 \%$ does not normally interfere with chemical analysis. However, difficulties can certainly arise regarding the determination of biological characteristics if contaminating substances are present. For example, it was shown that commercial preparations of LPS (commonly contaminated with $1 \%$ protein) lost all TLR-2-dependent activity after a further purification procedure. ${ }^{32}$

The heterogeneity of amphiphilic preparations presents a special problem in this regard, although this microheterogeneity is clearly a defining characteristic of bacterial amphiphiles. Of course, pure LTA solutions do not occur under physiological conditions. However, pure LTA preparations allow definition of the minimal structural LTA composition required for direct and clear-cut structure/function relationships.

\section{Possible consequences of fermentation conditions for LTA content and structure}

For a selection of bacteria, it has been described that culture conditions influence bacterial LTA content. The efficiency of the LTA extraction itself may also depend on culture 
conditions. ${ }^{19,33,34}$ The state at which the bacteria a re on the growth curve does not appear to influence the cellular LTA content, as was shown for Enterococcus faecalis and $S$. cureus. ${ }^{34}$ However, it should be noted that LTA release into the growth medium during the stationary phase leads to a reduction in the content of cellular LTA.

The cellular LTA content is influenced by the $\mathrm{pH}$ and the type of carbohydrate added to the culture medium. For example, a $\mathrm{pH}$ shift from 5.5 to 7 resulted in a 4 -fold increase in LTA content in cultures of Streptococcus mutons or Lactobacillus fermentum..$^{35.36}$ With in the same bacterial species and under specific concentration conditions, fructose appeared to promote LTA biosynthesis more than sorbitol or glucose..$^{37}$

The salt concentration in the culture medium has a large influence on the content of alanine ester substituents of the LTA of $S$ aureus. ${ }^{38}$ Thus, it could be shown that the degree of alanylation was reduced with increasing salt concentrations. Sodium and potassium chloride proved to be similarly effective in this respect. ${ }^{39}$ An analogous observation was made by changing the $\mathrm{pH}$ in $\mathrm{S}$ carreus cultures from 6 to 8 , resulting in a decrease in the degree of alanine substitution from 0.75 to $0.07,{ }^{40}$ probably as a result of alkali-catalyzed hydrolysis of the alanine esters.

Some of these descriptions may require further confirmation, as it has since been shown that the extraction of LTA from intact bacteria is incomplete. Furthermore, the effects of culture conditions on the LTA structure shou ld be re-appraised using the more gentle extraction with butanol at room temperature to conserve alanine content. ${ }^{16}$

\section{Necessity of cell disruption techniques for quantitative LTA yield}

Owing to the formerly unknown difficulty of quantitative extraction of LTA from bacteria, earlier assessments of the cellular LTA content of bacteria are probably too low. ${ }^{19,33,34}$ Values given range between $1-3 \%$ of the dry weight or $2-3 \%$ estimated by the ratio of phosphate- or glycerineLTA per gram dry weight. ${ }^{19,41}$ LTA from $S$. curreus makes up $7-9 \%$ of the total cellular phosphate..$^{42}$ Despite quantitative extraction, the yield of LTA from $S$. curreus and Enterococcus faecium obtained by inefficient disruption methods was only about $10 \%$ of the total LTA content. It became especially clear that efficient cellular disruption is essential when butanol extraction of $B$. subtilis LTA yielded significantly less than $10 \%$ of the total LTA content in the absence of sonication (authors' unpublished observation).

\section{Extraction of LTA}

The extraction of LTA or LPS from bacteria or extracellular supernatants is usually performed using aqueous

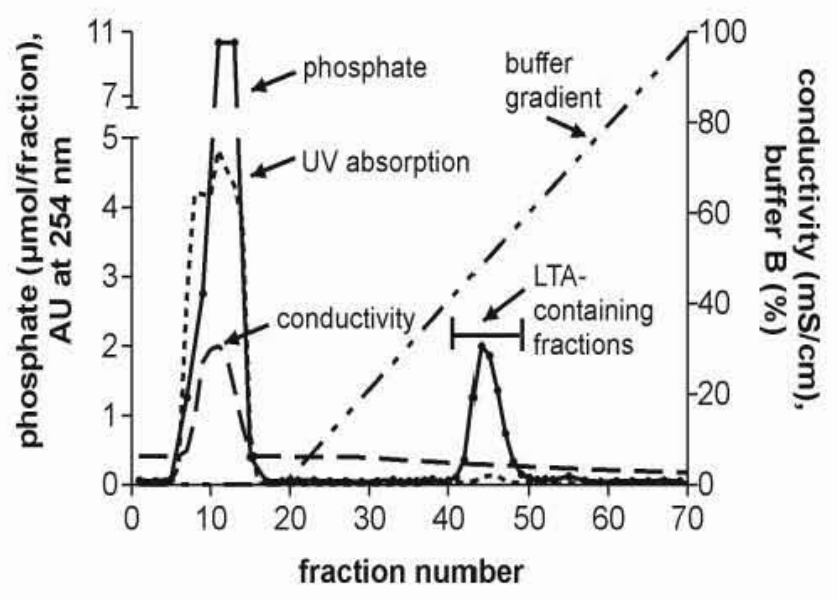

Fig. 4. Example of a LTA hydrophobic interaction chromatography (HIC) from S. aureus after $n$-butyl alcohol extraction. Bacterial extract was subjected to an octyl-Sepharose column with a buffer gradient from $15 \%$ to $60 \%$ n-propyl alcohol in $0.1 \mathrm{M}$ ammonium acetate buffer, $\mathrm{pH} 4.7$. UV detection was performed at $254 \mathrm{~nm}$.

butanol or phenol. Contaminations with other cellular components or medium components cannot be excluded.

1. Non-associated contominations (e.g. proteins, nucleic acids and polysaccharides) can generally be removed simply and completely by special forms of $\mathrm{HIC}^{19}$ Enzymatic digestion with proteinases and nucleases followed by gel filtration chromatography and ultracentrifugation have also been employed. ${ }^{43}$

2. Asscciated contaminations: the aptitude of amphiphiles to form complexes with lipids, proteins and polysaccharides by hydrophobic and/or ionic interactions presents a complex problem. ${ }^{44}$ Noncovalent lipid interactions (e.g. with polypropylene glycol [PPG], an anti-foaming agent commonly used for the cultivation of bacteria, which inhibits the immunostimulatory effects of LTA) can only be removed completely by time-consuming, multiple successive extractions with organic solvents such as butanol or dich loromethane. Although the solubility of polyglycerophosphate-LTA is low in these solvents, the use of large volumes of the solvent necessarily decreases the y ield. Monomerization of micellar protein or polysaccharide inclusions can be achieved by addition of detergents to the HIC buffer. Here, $n$-propylalcohol has proven useful as it has amphiphilic, detergent-like qualities, is both bactericidal and volatile under strong vacuum (authors' unpublished observations).

\section{Advantages of HIC}

1. Using a linear gradient for elution, the HICallows a onestep separation of acylated LTA from contaminating proteins, carbohydrates and lipids on the basis of 


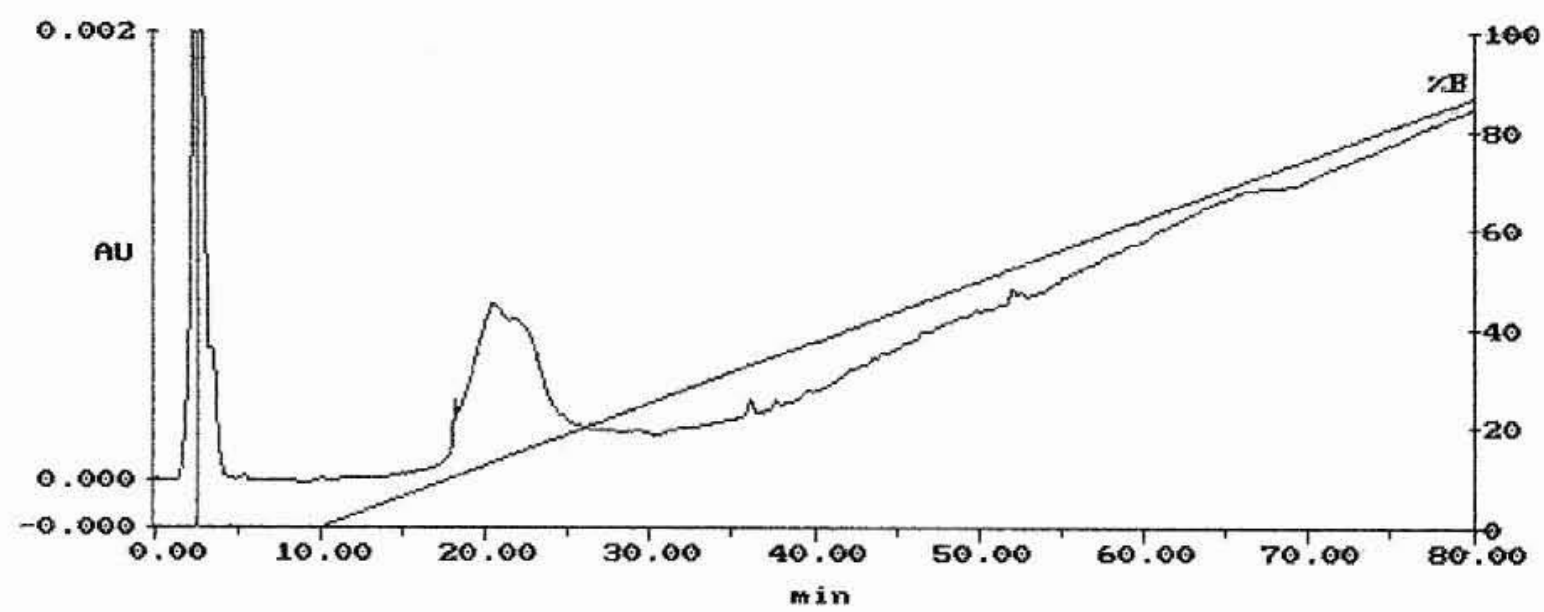

Fig. 5. Example of HPLC of LTA from S. aureus purified by HIC. LTA ( $400 \mu \mathrm{g})$ was subjected to an RP-8 col umn $\left(250 \mathrm{x} 4 \mathrm{~mm}\right.$, Merck) at $40^{\circ} \mathrm{C}$ with a buffer gradient from $100 \%$ water to $100 \%$ isopropyl alcohol. UV detection was performed at $230 \mathrm{~nm}$. LTA eluates at retention time of $21 \mathrm{~min}$.

octyl-Sepharose and 15-60\% n-propanol/ammonium acetate buffer ( $\mathrm{pH} 4.7-5.4),{ }^{45}$ as shown in Figure 4.

2. The purity of LTA obtained by HIC is similar to that produced by the vesicle technique (liposomes), the latter being successful only with larger quantities of LTA. ${ }^{46} \mathrm{~A}$ comparatively highly purified LTA can also be attained using 'detergent' anion exchange chromatography: this, however, requires a later, thorough removal of the detergent which, as shown by mass spectroscopy, is extremely difficult to achieve (authors' unpublished observations). The HIC can separate LTA subpopulations that differ in their degree of acylation and show increasing total hydrophobicity within the peak integral in the direction of the increasing gradient. A similar separation behavior is not given in the case of 'detergent' anion exchange chromatography or the vesicle technique. ${ }^{11}$

The mechanistic elution principle developed for purification by HC should also be applicable to fast separation of acylated LTAs and other bacterial amphiphilic molecules using reverse phase high performance liquid chromatography (HPLC) with C-8 or C-18 packed stationary phases, ${ }^{47}$ as shown in Figure 5.

\section{Disadvantages of $\mathrm{HIC}$}

Under chromatographic conditions at a $\mathrm{pH}$ of around 7, a lanine esters may be hydrolyzed during the purification process. In th is case, separation should be performed at a lower $\mathrm{pH} .{ }^{48}$ Due to the high absorption of the ammonium acetate buffer at wavelengths below $260 \mathrm{~nm}$, standardized, sensitive online UV detection of eluates containing LTA on an analytical to preparative scale is not straightforward. This can be solved with a flow-mode light scattering detector, which is sufficiently sensitive for use in prepa rative ch romatography (see also Fig. 4).

\section{Advantages of new LTA-NMR structural analysis methodology}

Non-destructive NMR spectroscopy has replaced indirect analysis methods requiring total hydrolysis of LTA, which were used in the 1970 s to $1990 \mathrm{~s}$. With those, different biogen ic sou rces of LTA and different preparation methods produced NMR results with limited comparability. Signal assignments were usually based on comparison of the ${ }^{1} \mathrm{H}$-chemical shifts of the isolated materials with the signals of known structural elements, making the identification of unexpected structural elements difficult.

The rapid methodological developments in the area of NMR spectroscopy in the last years (e.g. inverse detection or the use of pulsed field gradients) enable the assignment of extended $\mathrm{C}-\mathrm{H}$ spin systems and analysis of their covalent bonds. These strategies were previously seldom used for the analysis of the substitution pattern of LTA. Also, no studies with high field instruments $(\geq 600$ $\mathrm{MHz}$ ) have been reported in other publications on LTA to date. This high sensitivity allowed a quantitative NMR analysis of intact LTA including determining the ratio between the PGP chain, its substituents and the membrane anchor. ${ }^{16}$

\section{Chain length of the polyglycerophosphate backbone}

Type and relative amounts of the substituents of the PGP backbone could be determined directly from the ${ }^{1} \mathrm{H}-\mathrm{NMR}$. The anomeric proton of $N$-acetylglucosamine, the glycerol- $\mathrm{CH}$ of the alanine esters and the $\alpha$-methylene groups of the two fatty acids showed resonance signals in spectral regions that were not overlaid by other signals. Together with the integral over the glycerol signals, the average length of the PGP chain as well as the type and occurrence of the substituents was quantified (Table 1). 


\section{Alanylation}

Bound D-alanine could be differentiated from hydrolysed D-alanine. The kinetics of the ester hydrolysis was followed spectroscopically by ${ }^{1} \mathrm{H}-\mathrm{NMR}$.

\section{Glycosylation}

Type, amount and anomeric stereochemistry of the sugar substituents could be characterized by two dimensional homo- and heteronuclear NMR spectra. After selective de-alanylation, it could be shown that the sugar substituents were bound to the glycerophosphate backbone with a certain distribution and not en bloc.

\section{Membrane anchor}

The isolated membrane anchor gentiobiosyl-diacylglycerol was used to determine the length and branching of the fatty acids. ${ }^{16}$

Open questions which can now be addressed include whether the structure of LTA is modified under different culture conditions, how selective modification of LTA influences its function or stability and how the overall charge of LTA influences its spatial structure. More gentle methods of ionization (i.e. infrared lasers and nano-electrospray) may enable mass spectroscopic analysis of intact LTA.

\section{Conclusions}

Improved characterization of the chemical structures of bacterial agonists, especially LTA and LPS, will help to elucidate the structural requirements for the activation or inhibition of receptors on immune cells, such as the Tolllike receptors. The investment into structure/function relationships for LTA until now does not match, by far, the efforts expended for its Gram-negative counterpart. Newly available advanced analytical methods, however, allow these studies to be carried out in a most efficient manner. This will represent a valuable complement to the functional characterization of this Gram-positive endotoxin.

\section{ACKNOWLEDGEMENTS}

We would like to thank Prof. Dr Richard R. Schmidt, Prof. Dr Armin Geyer, Dr Andreas Stadelmaier and the late Prof. Dr Werner Fischer.

\section{REFERENCES}

1. Movat HZ, Cybulsky MI, Colditz IG, Chan MK, Dinarello CA. Acute inflammation in Gram-negative infection: endotoxin, interleukin 1, tumor necrosis factor, and neutrophils. Fed Proc 1987; 46: 97-104.
2. Bone RC. Gram-positive organisms and sepsis. Arch Intern Med 1994; 154: 26-34.

3. Opal SM, Cohen J. Clinical Gram-positive sepsis: does it fundamentally differ from Gram-negative bacterial sepsis? Crit Care Med 1999; 27: 1608-1616.

4. Williams DH, Bardsley B. Die Vancomycin-Antibiotica und der Kampf gegen resistente Bakterien. Angew Chem 1999; 111: 1264-1286.

5. Harris TN, Harris S. Agglutination by human sera of erythrocytes incubated with streptococcal culture concentrates. J Bacteriol 1953; 66: $159-165$.

6. Pakula R, Walczak W. An erythrocyte-sensitising factor common to staphylococci and haemolytic streptococci. Acta Microbiol Pol $1955 ; 4: 235-243$.

7. Jackson RW, Moskowitz M. Nature of a red cell sensitizing substance from streptococci. J Bacteriol 1966; 91: 2205-2209.

8. Dishon T, Finkel R, Marcus Z, Ginsburg I. Cell-sensitizing products of streptococci. Immunology 1967; 13: 555-564.

9. Wicken AJ, Knox KW. Lipoteichoic acids: a new class of bacterial antigen. Science 1975; 187: 1161-1167.

10. Hew ett MJ, Knox KW, Wicken AJ. Studies on the group F antigen of lactobacilli: detection of antibodies by haem agglutination. J Gen Microbiol 1970; 60: 315-322.

11. Leopold K, Fischer W. Hydrophobic interaction chromatography fractionates lipoteichoic acid according to the size of the hydrophilic chain: a comparative study with anion-exchange and affinity chromatography for suitability in species analysis. Anal Biochem 1992; 201: 350-355.

12. Fischer W. Lipoteichoic acids and lipoglycans. In: Ghuysen J-M, Haken beck R. (eds) Bacterial Cell Wall. Amsterdam: Elsevier Science, 1994; 199-215.

13. Keller R, Fischer W, Keist R, Bassetti S. Macrophage response to bacteria: induction of marked secretory and cellular activities by lipoteichoic acids. Infect Immun 1992; 60:3664-3672.

14. Kusunoki T, Hailman E, Juan TS, Lichenstein HS, Wright SD Molecules from Staphylococcus aureus that bind CD14 and stimulate innate immune responses. $J$ Exp Med 1995; 182: 1673-1682.

15. Kusunoki T, Wright SD. Chemical characteristics of Staphylococcus aureus molecules that have CD14-dependent cell-stimulating activity. J Immunol 1996; 157: 5112-5117.

16. Morath S, Geyer A, Hartung T. Structure-function relationship of cytokine induction by lipoteichoic acid from Staphylococcus aureus. J Exp Med 2001; 193: 393-397.

17. Morrison DC, Leive L: Fractions of lipopolysaccharide from Escherichia coli O111:B4 prepared by two extraction procedures. J Biol Chem 1975; 250: 2911-2919.

18. Okamoto M, Kaji R, Kasetani Het al. Purification and characterization of interferon-gamma-inducing molecule of $\mathrm{OK}$ 432 , a penicillin-killed streptococcal preparation, by monoclonal antibody neutralizing interferon-gamma-inducing activity of $\mathrm{OK}$ 432. J Immunother 1993; 13: 232-242.

19. Fischer W, Koch HU, Haas R. Improved preparation of lipoteichoic acids. Eur J Biochem 1983; 133: 523-530.

20. Morath S, Geyer A, Spreitzer I, Hermann C, Hartung T. Structural decomposition and heterogeneity of com mercial lipoteichoic acid preparations. Infect Immun 2002; 70: 938-944.

21. Hermann C, Spreitzer I, Schroder NW et al. Cytokine induction by purified lipoteichoic acids from various bacterial species - role of $\mathrm{LBP}, \mathrm{sCD} 14, \mathrm{CD} 14$ and failure to induce IL-12 and subsequent IFNgamma release. Eur J Immunol 2002; 32: 541-551.

22. Stadelmaier A, Morath S, Hartung T, Schmidt RR. Synthesis of the first fully active lipoteichoic acid. Angew Chem Int Edn Engl 2003; 42: 916-920.

23. Morath S, Stadelmaier A, Geyer A, Schmidt RR, Hartung T. Synthetic lipoteichoic acid from Staphylococcus aureus is a 
potent stimulus of cytokine release. $J$ Exp Med $2002 ; 195$ : $1635-1640$.

24. Lehner MD, Morath S, Michelsen KS, Schumann RR, Hartung T. Induction of cross-tolerance by lipopolysaccharide and highly purified lipoteichoic acid via different Toll-like receptors independent of paracrine mediators. J Immunol 2001; 166: 5161-5167.

25. Deininger S, Stadelmaier A, von Aulock S et al. Definition of structural prerequisites for lipoteichoic acid-inducible cytokine induction by synthetic derivatives. $J$ Immunol $2003 ; 170$ : 41344138 .

26. Ellingsen E, Morath S, Flo T et al. Induction of cytokine production in human $\mathrm{T}$ cells and monocytes by highly purified lipoteichoic acid: involvement of Toll-like receptors and CD14. Med Sci Monit 2002; 8: BR149-BR156.

27. Schroder NW, Morath S, Alexander C et al. Lipoteichoic acid (LTA) of Streptococcus pneumoniae and Staphylococcus aureus activates immune cells via Toll-like receptor (TLR)-2, lipopolysaccharidebinding protein (LBP), and CD14, whereas TLR-4 and MD-2 are not involved. J Biol Chem 2003; 278: 15587-15594.

28. Hoebe K, Georgel P, Rutschmann S et al. CD36 is a sensor of diacylglycerides. Nature 2005; 433: 523-527.

29. von Aulock S, Morath S, Hareng L et al. Lipoteichoic acid from Staphylococcus aureus is a potent stimulus for neutrophil recruitment. Immunobiology 2003; 208: 413-422.

30. Mattsson E, Hartung T, Morath S, Egesten A. Highly purified lipoteichoic acid from Staphylococcus aureus induces procoagulant activity and tissue factor expression in human monocytes but is a weak inducer in whole blood: comparison with peptidoglycan. Infect Immun 2004; 72: 4322-4326.

31. Lynch NJ, Roscher S, Hartung T et al. L-Ficolin specifically binds to lipoteichoic acid, a cell wall constituent of Grampositive bacteria, and activates the lectin pathway of complement. J Immunol 2004; 172: 1198-1202.

32. Hirschfeld M, Ma Y, Weis JH, Vogel SN, Weis JJ. Repurification of lipopolysaccharide eliminates signaling through both human and murine Toll-like receptor 2. J Immunol 2000; 165: 618-622.

33. Huff E. Lipoteichoic acid, a major amphiphile of Gram-positive bacteria that is not readily extractable. $J$ Bacteriol $1982 ; 149$ : 399-402.

34. Fischer W, Koch HU. Alanine ester substitution and its effect on the biological properties of lipoteichoic acids. In: Wicken GDSaAJ. (ed) Chemistry and Biological Activities of Bacterial Surface Amphiphiles. New York: Academic Press, 1981; 181-194.

35. Jaber BL, Barrett TW, Cendoroglo Neto Met al. Removal of cytokine inducing substances by polymyxin-B immobilized polystyrene-derivative fibers during in vitro hem operfusion of $10 \%$ human plasma containing Staphylococcus aureus challenge. Asaio J 1998; 44: 48-53.

36. Wicken AJ, Broady KW, Ayres A, Knox KW. Production of lipoteichoic acid by lactobacilli and streptococci grown in different environments. Infect Immun 1982; 36: 864-869.

37. Hardy L, Jacques NA, Forester Het al. Effect of fructose and other carbohydrates on the surface properties, lipoteichoic acid production, and extracellular proteins of Streptococcus mutans Ingbritt grown in continuous culture. Infect Immun 1981; 31: 78-87.

38. Fischer W, Rosel P. The alanine ester substitution of lipoteichoic acid (LTA) in Staphylococcus aureus. FEBS Lett 1980; 119: 224-226.

39. Koch HU, Doker R, Fischer W. Maintenance of D-alanine ester substitution of lipoteichoic acid by reesterification in Staphylococcus aureus. J Bacteriol 1985; 164: 1211-1217.

40. MacArthur AE, Archibald AR. Effect of culture $\mathrm{pH}$ on the Dalanine ester content of lipoteichoic acid in Staphylococcus aureus. $J$ Bacteriol 1984; 160: 792-793.

41. Wicken AJ, Gibbens JW, Knox KW. Com parative studies on the isolation of membrane lipoteichoic acid from Lactobacillus fermenti. J Bacteriol 1973; 113: 365-372.

42. Fischer W. Lipoteichoic acid and lipids in the mem brane of Staphylococcus aureus. Med Microbiol Immunol (Berl) 1994; 183: 61-76.

43. Galanos C, Luderitz O, Westphal O. Preparation and properties of a standardized lipopolysaccharide from Salmonella abortus equi (Novo-Pyrexal). Zentralbl Bakteriol [Orig A] 1979; 243: 226-244.

44. Wicken AJ, Knox KW. Bacterial cell surface amphiphiles. Biochim Biophys Acta 1980; 604: 1-26.

45. Fischer W. One-step purification of bacterial lipid macroamphiphiles by hydrophobic interaction chromatography. Anal Biochem 1991; 194: 353-358.

46. Silvestri LJ, Craig RA, Ingram LO, Hoffm ann EM, Bleiweis AS. Purification of lipoteichoic acids by using phosphatidyl choline vesicles. Infect Immun 1978; 22: 107-118.

47. Muhlradt PF, Kiess M, Meyer H, Sussmuth R, Jung G. Isolation, structure elucidation, and synthesis of a macrophage stimulatory lipopeptide from Mycoplasma fermentans acting at picomolar concentration. J Exp Med 1997; 185: 1951-1958.

48. Fischer W, Koch HU, Rosel P, Fiedler F. Alanine ester-containing native lipoteichoic acids do not act as lipoteichoic acid carrier. Isolation, structural and functional characterization. $J$ Biol Chem 1980; 255: 4557-4562. 